\title{
Effect of Spun Velocities and Composition on the R-phase and Thermomechanical Behavior in Ti-Ni Ribbons Electrically Heated
}

\author{
Enrique López Cuellar * *, Esaú Nuñez Mendoza ${ }^{a}$, Carlos José De Araújo ${ }^{b}$, \\ Beatriz Cristina López, Walle ${ }^{a}$, Jorge Otubo ${ }^{c}$, Cezar Gonzalez ${ }^{d}$ \\ ${ }^{a}$ Centro de Investigación Innovación y Desarrollo en Ingeniería y Tecnología - CIIDIT, \\ Facultad de Ingeniería Mecánica y Eléctrica - FIME, Universidad Autónoma de Nuevo León-UANL, \\ Ciudad Universitaria, C.P. 66451, San Nicolás de los Garza, N.L., México \\ ${ }^{b}$ Universidade Federal de Campina Grande - UFCG, Av. Aprigio Veloso 882, \\ Bairro Universitário, C.P. 10069, Campina Grande, Paraíba, Brazil \\ 'Instituto Tecnológico de Aeronáutica - ITA, Praça Marechal Eduardo Gomes, 50, \\ CEP 12228-900 - São José dos Campos, SP, Brazil \\ ${ }^{d}$ Universidade Federal de Pernambuco - UFPE, Av. Acadêmico Hélio Ramos, \\ $s / n$, Cidade Universitária, Recife, PE, Brazil
}

Received: January 13, 2016; Accepted: March 7, 2016

This work deals with structural, electrical and mechanical characterization of Ti-50.13Ni and Ti-49.62Ni (at.\%) shape memory alloys (SMAs) fabricated at different circumferential wheel velocities. The effect of wheel velocity, chemical composition and heat treatments are investigated. The characterization of crystallographic phases of the Ti-Ni ribbons was carried out using X-ray diffraction. Electrical resistance variations as function of temperature $(\Delta R / R \%)$ were analyzed using a non-commercial technique, which consists in a thermal-adjustable bath apparatus revealing the temperatures of $\mathrm{B} 2 \rightarrow \mathrm{R} \rightarrow \mathrm{B} 19^{\prime}$ two stage transformation, whereby the presence of R-phase can be definitively confirmed. The Stress-Assisted Two-Way Memory Effect was measured by an own designed apparatus with an Linear Variable Differential Transformer captor and a current controlled heating, and results indicate that the as-spun condition, promotes the Stress-Assisted Two-Way Memory Effect. On the other hand, increments in Ni content tend to decrease transformation temperatures and high wheel velocities help to the R-phase formation.

Keywords: Ti-Ni Ribbons, Melt-spinning, R-phase, Electrical Resistance, Joule Effect, Shape Memory Alloys

\section{Introduction}

Near equiatomic Ti-Ni shape memory alloys (SMAs) are well known to exhibit a thermoelastic martensitic transformation associated to B2 to R-phase and B19', with superelastic (SE) and a shape memory effect (SME) ${ }^{1-4}$. In these SMAs, the R-phase martensitic transformation is known to precede the $\mathrm{B} 2 \rightarrow \mathrm{B} 19^{\prime}$ martensitic transformation under certain conditions, as thermal cycling and thermomechanical treatments mainly. The existence of the R-phase depends on several factors like composition, thermal history cycling, degree of cold work and solution treatment of the sample. In most cases the $\mathrm{R}$-phase is not very pronounced and several thermal cycles are required to make it appear more clearly ${ }^{5}$.

Widespread results of SME have shown in the literature, a simple step transformation related to the $\mathrm{B} 2 \rightarrow \mathrm{B} 19$ ' sequence (as in $\mathrm{Ti}-\mathrm{Ni}, \mathrm{Ti}-\mathrm{Ni}-\mathrm{Cu}_{5}$ alloys), however in some cases, as in Ti-Ni alloys, two peaks of martensitic transformations in DSC curves could be favored (B2 $\rightarrow \mathrm{R} \rightarrow \mathrm{B} 19^{\prime}$ ) basically in three ways: by cold work, by ageing of the alloys with higher Ni content, and by the addition of a third element e.g.

*e-mail: enlopez_73@yahoo.com
Fe. Other results have proven that the position of the peaks according to the temperature could be affected by thermal and thermomechanical cycling and heat treatments, causing an increase of the temperature of the peak of B2 and an overlapping of both peaks in DSC, even some authors have reported that R-phase transformation could disappear ${ }^{6,7-9}$. When this overlapping of phases takes place, techniques as electrical resistivity variation has greatly helped to identify the R-phase and the sequence of transformation can be followed ${ }^{10-11}$. Electrical resistivity variations of SMA during thermal or mechanical tests have been investigated for a long time, showing that these variations are considered to depend mainly on the volume fractions of the austenite and martensite phases. In addition to this, measurements of electrical resistance (ER) with temperature have commonly been used to evaluate transformation temperatures of SMAs ${ }^{12-13}$.

On the other hand, R-phase martensitic transformations in Ti-Ni SMA are known to be attractive for its small transformation hysteresis, high stability during thermomechanical cycling and superior functional fatigue resistance. Some authors have suggested methods as melt-spinning for inducing the $\mathrm{B} 2 \rightarrow \mathrm{R}$ 
martensitic transformation ${ }^{14-15}$. Moreover, it is known that mechanical properties as Stress-Assisted Two-Way Memory Effect (SATWME) in Ti-Ni alloys are very important for the development of smart actuators manufactured from this special kind of non-conventional material ${ }^{7}$. However, R-phase transformation is not fully beneficial for those applications where a position control is required (e.g. actuators) $)^{4-5,14,16-20}$.

Based on aforementioned backgrounds, the objectives of this paper are: to determine the influence of the cooper wheel velocity, heat treatment and chemical composition over the thermal and electrical behavior of the ribbons, and to estimate which conditions are the more interesting for possible applications in the field of micro-actuators or micro-robotics, taking into account only the SATWME of the ribbons electrically heated, which could be a normal situation in the field of actuators. In addition to this, to investigate the electric resistance behavior of $\mathrm{Ti}-\mathrm{Ni}$ ribbons presenting the $\mathrm{R}-$ phase transformation.

\section{Experimental Section}

The conventional vacuum induction melting (VIM) process was employed to elaborate binary Ti-Ni SMAs. Two buttons were fabricated by VIM with nominal composition of Ti-50.13 Ni and Ti-49.62Ni (at.\%) and were called M1 and M2, respectively. It is important to mention that elements used for this investigation have high purity (Grade 1 Ti, 99.80 wt.\% and electrolytic Ni, 99.95 wt.\%). Their transformation temperatures obtained by DSC are presented in table $1^{21-22}$. After that, the buttons were placed in a melt-spun equipment to produce ribbons.

The melt-spun ribbons were produced under a $200 \mathrm{mbar}$ argon atmosphere using a quartz crucible with a nozzle diameter of $1.0 \mathrm{~mm}$; the melt was ejected onto the surface of a polished copper wheel having a tangential wheel speed fixed at 30,40 and $50 \mathrm{~m} / \mathrm{s}$. The distance between the nozzle and the copper wheel was $0.5 \mathrm{~mm}$. The thickness average of the ribbons varied from 30 up to $50 \mu \mathrm{m}$, where those with lower thickness and lower width were the ribbons produced at $50 \mathrm{~m} / \mathrm{s}^{23}$. With the aim to homogenize the microstructure and decrease defects like dislocations generated during melt spinning, samples were heat treated at $350^{\circ} \mathrm{C}$ during 1 and 5 hours. Table 2 gives some characteristics of the obtained ribbons, focusing on the chemical composition which was measured by energy dispersive x-ray (EDX) in order to corroborate the composition initially used in the VIM process to obtain the buttons M1 and M2. As can be seen, EDX results are very close to the initial composition, proving that M1 is rich in $\mathrm{Ni}$ and M2 in Ti, even the $95 \%$ of EDX accuracy.

Crystallographic planes and phases were investigated by X-ray Diffraction (XRD) using $\mathrm{CuK} \alpha$ radiation (Bruker Advanced X-ray Solutions D8) at a rate of $6.0 \% \mathrm{~min}$. ER measurements using the four wires ohms method were carried out in a thermal-adjustable bath containing silicone oil for thermal cycling with a calibrated $\mathrm{K}$ type thermocouple to measure the temperature. The accuracy in temperature measurement is around $\pm 1.1^{\circ} \mathrm{C}$ to $2.2^{\circ} \mathrm{C}$. The measurement system is also equipped with a controlled power supply to maintain a constant electrical current in the ribbons and a data acquisition device (Agilent, model 34970A) for storage the voltage drop during thermal cycling. The temperature range was configured from $90^{\circ} \mathrm{C}$ to $-10^{\circ} \mathrm{C}$ in order to study the range were the martensitic transformation takes place. The Ti-Ni ribbons were connected in series to undertake five measurements in one run. The employed electrical current was of the order of $400 \mathrm{~mA}$, causing an initial voltage drop of about $600 \mathrm{mV}$ on each ribbon ${ }^{24}$. Finally, to study the SATWME under constant load, thermomechanical cycles between the Austenite (A) and Martensite (M) phases were carried out using an apparatus developed in our laboratory through a special program, which is connected to a Linear Variable Differential Transformer (LVDT) device for measuring small displacements. The sample is held with jaws attached to a pulley system with a constant load. When the electric current passes through the sample, the ribbon is heated and transformed into austenite, the cycle is completed by cooling in air at room temperature by removing the current slowly. Furthermore, the strain at high and low temperature is measured with the LVDT. Data acquisition of electrical current and deformation is computer controlled, and is possible to construct a curve of strain vs. current density.

Table 1. Phase transformation temperatures of the row materials ${ }^{\mathrm{a}}$.

\begin{tabular}{ccccc}
\hline Alloy & As $\left({ }^{\circ} \mathbf{C}\right)$ & Af $\left({ }^{\circ} \mathbf{C}\right)$ & Ms $\left({ }^{\circ} \mathbf{C}\right)$ & Mf $\left({ }^{\circ} \mathbf{C}\right)$ \\
\hline M1 & 58.0 & 77.9 & 49.7 & 34.9 \\
M2 & 67.6 & 87.8 & 59.3 & 44.0 \\
\hline
\end{tabular}

${ }^{\text {a }}$ Grade $1 \mathrm{Ti}, 99.80$ wt.\% purity (balance); electrolytic Ni, 99.95 wt.\% purity.

Table 2. Thermal and chemical characteristics of the obtained ribbons

\begin{tabular}{|c|c|c|c|c|c|c|c|}
\hline \multirow{2}{*}{ Alloys } & \multirow{2}{*}{$\begin{array}{c}\text { Tangential } \\
\text { Wheel } \\
\text { Speed, m/s }\end{array}$} & \multirow{2}{*}{ HT-1 } & \multicolumn{2}{|l|}{ EDX } & \multirow{2}{*}{ HT-2 } & \multicolumn{2}{|c|}{ EDX } \\
\hline & & & $\mathrm{Ti}$ (at \%) & $\mathrm{Ni}$ (at \%) & & $\mathrm{Ti}($ at $\%)$ & $\mathrm{Ni}($ at \%) \\
\hline \multirow{3}{*}{ M1 Ti-50.13 at. \% Ni } & 30 & & 49.7 & 50.3 & \multirow{3}{*}{$\begin{array}{c}350^{\circ} \mathrm{C} \\
5 \mathrm{~h}\end{array}$} & 49.3 & 50.7 \\
\hline & 40 & $350^{\circ} \mathrm{C}-1 \mathrm{~h}$ & 49.5 & 50.5 & & 49.7 & 50.3 \\
\hline & 50 & & 49.1 & 50.9 & & 49.7 & 50.3 \\
\hline \multirow{3}{*}{ M2 Ti-49.62 at. $\% \mathrm{Ni}$} & 30 & & 50.6 & 49.4 & \multirow{3}{*}{$\begin{array}{c}350^{\circ} \mathrm{C} \\
5 \mathrm{~h}\end{array}$} & 51.0 & 49.0 \\
\hline & 40 & $350^{\circ} \mathrm{C}-1 \mathrm{~h}$ & 50.3 & 49.7 & & 51.7 & 48.3 \\
\hline & 50 & & 50.4 & 49.6 & & 50.2 & 49.8 \\
\hline
\end{tabular}


Then, the SATWME could be obtained from the difference between the strain of the phases at low and high temperature.

\section{Results and Discussion}

\subsection{XRD results of the as-spun melted and heat treated Ti-Ni SMA ribbons}

In order to study the phases presented in the $\mathrm{Ti}-\mathrm{Ni}$ SMA ribbons, X-ray diffractions were performed at room temperature and results are show in figure 1 . These patterns consist on peaks corresponding to the martensite phase B19'
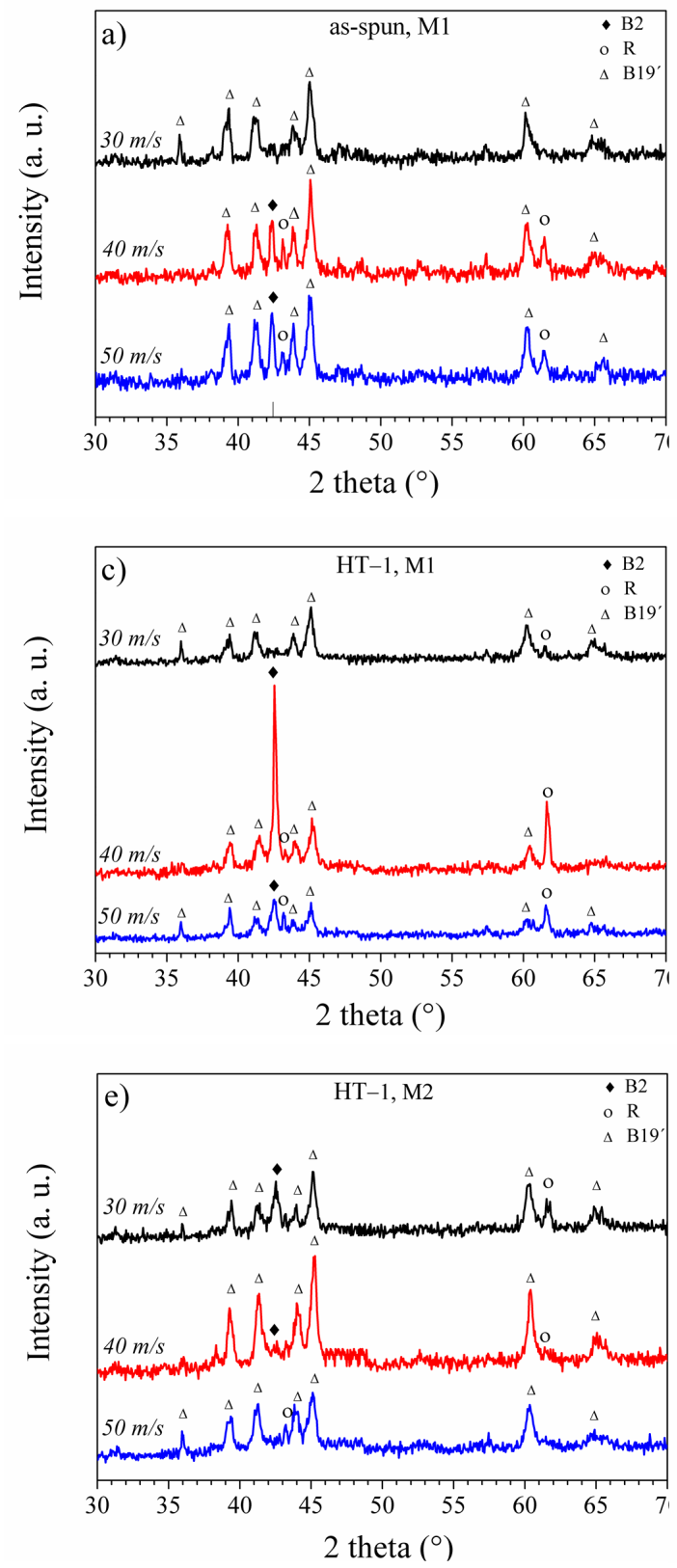

with a monoclinic structure which suggests that $M s$ is above room temperature for all cases. However, in other states, some peaks correspond to the austenite phase B2 with a cubic structure are also present, as well as, R-phase which possess a rhombohedral structure. For those cases it can be inferred that $M f$ is below room temperature. Moreover, $\mathrm{R}$-phase is favored as defects are promoted. This is exactly what is happening in the ribbons of the as-spun state of M1 and M2 (figure 1a-b), it can be seen that at lowest tangential wheel speed of $30 \mathrm{~m} / \mathrm{s}$, only peaks corresponding to B19'appears, because this is the condition that should
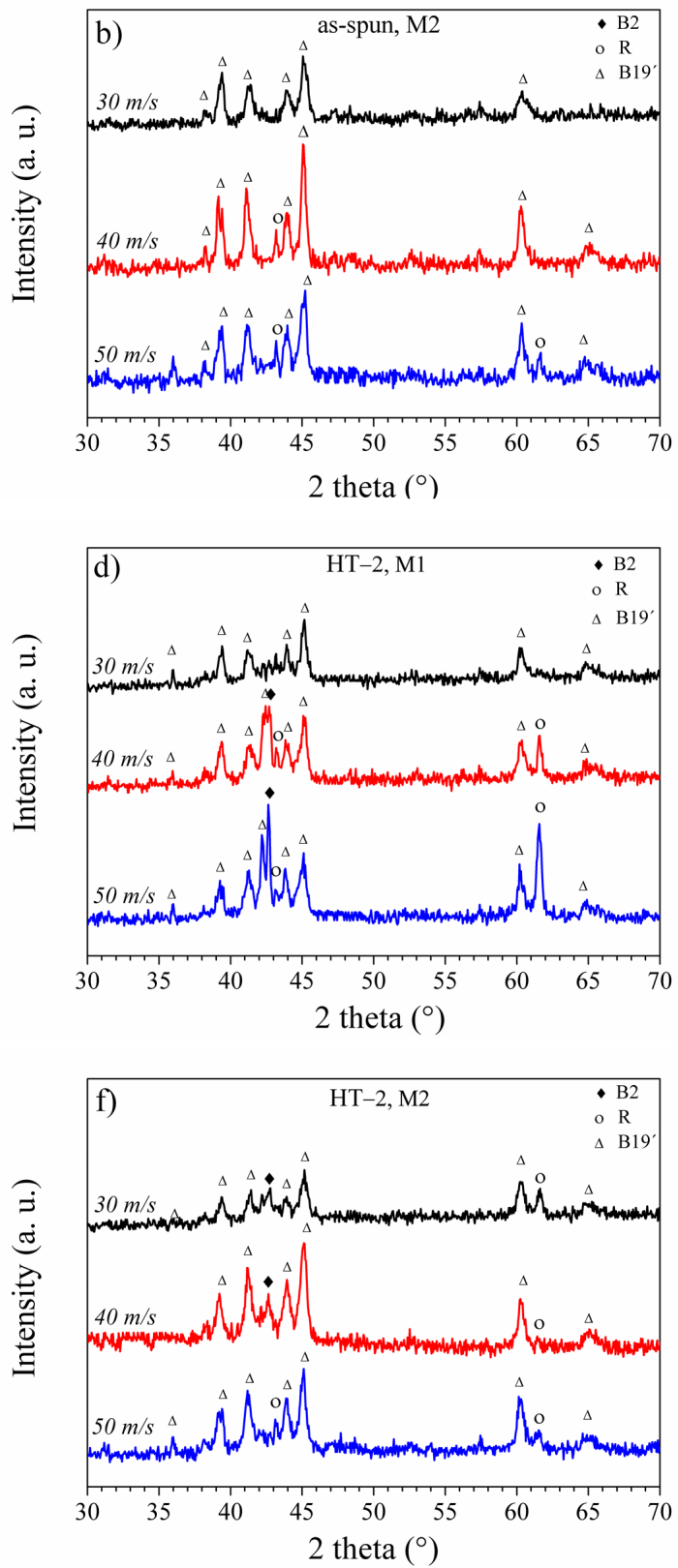

Figure 1. X-ray diffraction analyses of Ti-Ni ribbons of (a-b) as-spun, (c-d) M1 with HT-1 and HT-2, (e-f) M2 with HT-1 and HT-2, respectively. 
present larger grain size and higher $M f^{1}$, as it was previously reported by Nuñez Mendoza ${ }^{25}$. In the XRD patterns of M1 at 40 and $50 \mathrm{~m} / \mathrm{s}$ small diffraction peaks corresponding to the B2 phase and R-phase start to appear at $42.37^{\circ}, 43.18^{\circ}$ and $61.53^{\circ}$ respectively, corresponding to the planes B2 (110), $\mathrm{R}(11 \overline{2})$ and $\mathrm{R}(22 \overline{2})$ and it can be said that $M f$ temperatures decreased with wheel speed increasing, which can promote the presence of $\mathrm{R}$-phase and $\mathrm{B} 2$ at room temperature in XRD patterns. For M2 Ti-rich alloy, the increasing of the wheel speed defects should be the cause that promotes the development of the R-phase. Now, the apparition of all the phases (B2, R and $\mathrm{B}^{\prime} 9^{\prime}$ ) in the other XRD patterns for all the heat treated samples from figure $\mathrm{c}-\mathrm{f}$, is explained because the $M f$ for these ribbons is lower than the $M f$ for the ribbons as-spun conditions. Moreover, the peak at $61.53^{\circ}$ corresponding to the R-phase shows an increase in almost all states of the M1 compared with peaks of M2, which confirm that the Ni promotes the presence of the R-phase. With the only exception of XRD pattern of the HT1-M1 at $40 \mathrm{~m} / \mathrm{s}$, it can be appreciated that peaks of the B19' phase are lightly higher when the temperature or the time of the HT increases. This suggests that with higher HT in temperature and time, less defects and more transformed martensite at room temperature should be expected, and possibly the R-phase could disappear.

\subsection{ER variations of Ti-Ni shape memory alloy ribbons}

Figure 2 shows the curves of ER variation $(\Delta \mathrm{R} / \mathrm{R})$ as a function of temperature for analyzed Ti-Ni ribbons described in table 2 at $30 \mathrm{~m} / \mathrm{s}$ and $50 \mathrm{~m} / \mathrm{s}$. As expected, in comparison between $\mathrm{Ti}-\mathrm{Ni}$ and $\mathrm{Ti}-\mathrm{Ni}-\mathrm{Cu}$ SMAs, the
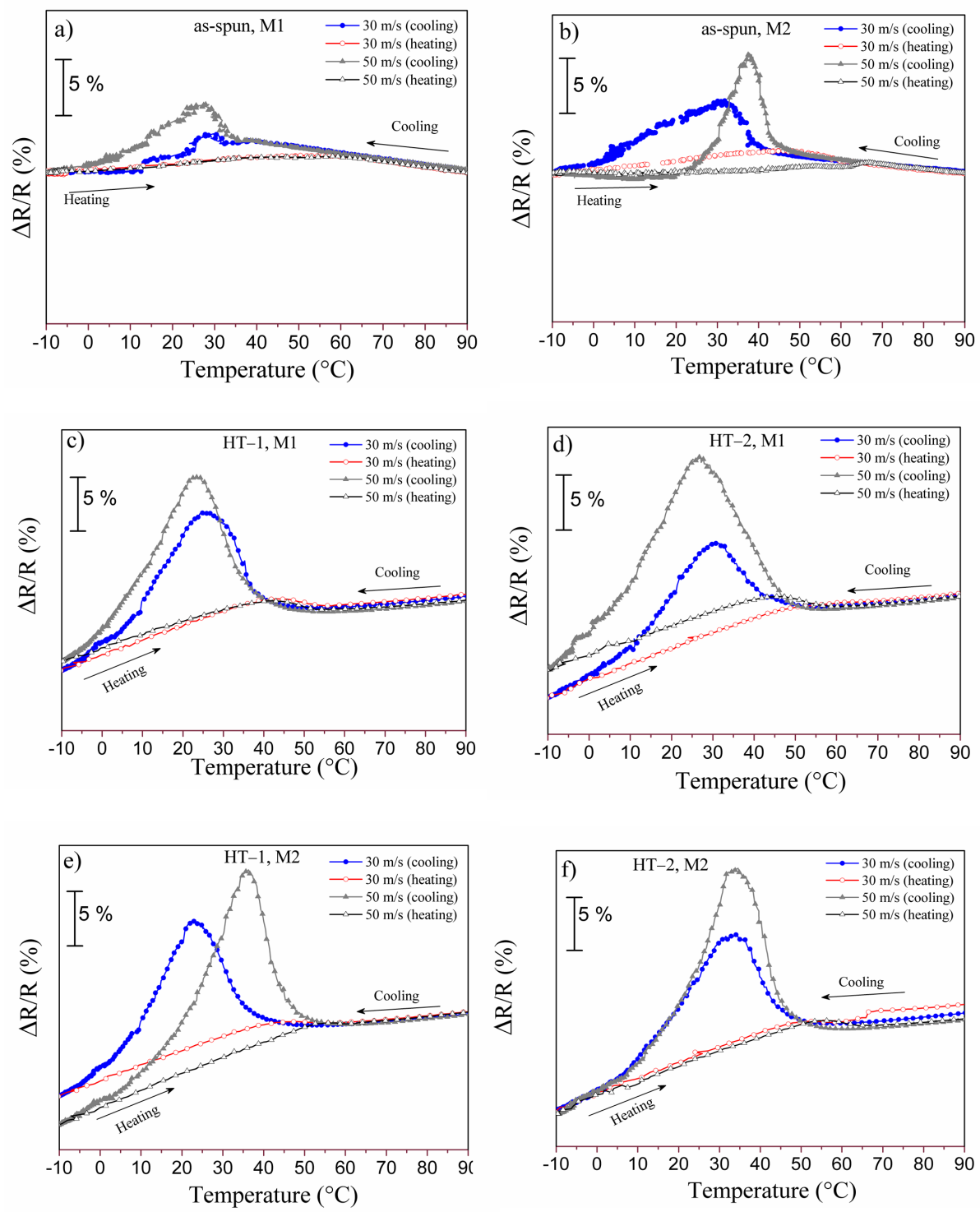

Figure 2. Dependence of the electrical resistance versus temperature curves corresponding to the (a-b) as-spun M1 and M2, (c-d) M1 with HT-1 and HT-2, (e-f) M2 with HT-1 and HT-2, respectively; in a complete thermal cycle. 
curves do not exhibit the typical forward and reverse "S" shape of classical martensitic transformations of SMAs, as it was demonstrated recently by De Araújo et al. ${ }^{26}$. This is due because the R-phase of samples M1 and M2, causes an abrupt augmentation of the electrical resistance of the material, while by adding $\mathrm{Cu}$ at around 5\%, the R-phase disappears and this promotes curves with the "S" shape in the electrical behavior during termomechanical tests at constant stress ${ }^{26}$.

From literature, a rapid increase in electrical resistance while cooling is associated to $\mathrm{R}-$ phase formation ${ }^{27}$. It has been reported that the appearance of $\mathrm{R}$-phase on $\mathrm{Ti}-\mathrm{Ni}$ is due to the increase in $\mathrm{Ni}$ content, thermal cycling and aging. Besides, the microstructural defects produced during the melt-spinning at high speed enhance the formation of $\mathrm{R}$-phase ${ }^{28}$, which corroborates the results obtained in figure 2 . The appearance of martensitic R-phase is characterized by the high increase in ER (Electrical Resistance) and then a decrease when B19'martensitic phase appears ${ }^{29}$. The results show that higher variation of ER was observed by those heat-treated ribbons, meaning that more $\mathrm{R}$-phase is developed, which is in agreement with XRD results. It can be noted that for ribbons of M1 and M2 as-spun melted state (figure $2 \mathrm{a}-\mathrm{b}$ ), curves show undefined phase changes during cooling with small percentage of ER variation in the sequence $\mathrm{B} 2 \rightarrow \mathrm{R} \rightarrow \mathrm{B} 19^{\prime}$ martensic transformation. This fact is also in agreement with results of XRD presented in figure 1, where, as-spun ribbons only show small signs of R-phase, and the fact that materials with no heat treatment normally present a heterogeneous microstructure, was solved applying heat treatments (HT-1 and HT-2) resulting well-defined curves as shown in figure $2 \mathrm{c}-\mathrm{f}$, where there is a clear increment in the $\Delta \mathrm{R} / \mathrm{R}$ axis during $\mathrm{B} 2 \rightarrow \mathrm{R}$ transformation, and then a dramatic decrease of $\Delta R / R$ during $R \rightarrow B 19^{\prime}$. These results are opposite to those expected about that dislocations promote the R-phase and that higher heat treatments should decrease defects and also R-phase. But results seems to indicate that this two HT in the M1 and M2 ribbons, allow an increase in the amount of transformation because in the as-spun ribbons, the transformation is strongly blocked, and this could be the reason of this increase, not only of the R-phase but also of the martensite phase. In this sense, as perspective in a future work, higher HTs must be done in order to elucidate this point, because authors have suggested that higher and longer heat treatments are needed to suppress de R-phase ${ }^{7}$. On other hand, while cooling, the ER increased suddenly at $R s$, reached the maximum $\Delta \mathrm{R} / \mathrm{R}$ value at $M s$. On other hand, as can be seen ribbons annealed at HT-2 show the maximum ER variation for the most cases, giving more than $13 \%$, in relation with the $\mathrm{B} 2$ austenite parent phase.

Although others characterization techniques like DSC or $\mathrm{XRD}$ can show a slight evidence of $\mathrm{R}$-phase, this phenomenon could not be completely followed. Contrary, as it is shown in figures $2 \mathrm{a}$ to $2 \mathrm{f}$, at less for ribbons Ti-Ni with this chemical composition and heat treatments, the use of techniques as 4-wires method (adapted to this non-commercial apparatus developed by Lima et al., ${ }^{24}$ ) is helpful to study all the kinetic of transformation of $\mathrm{R}$-phase while the temperature is changing. Analyzing now those ribbons subjected at HT-1 and HT-2 some issues can be mentioned. It is remarkable that a longer heat treatment tends to stabilize TTRs for the M1 and M2 regardless the wheel speed. Then, Ti-Ni ribbons examined in this work can be used as high precision devices in a width range of temperatures.

\subsection{Recovery strain response of $\mathrm{Ti}-\mathrm{Ni}$ ribbons}

Coupled measures of memory effects and physical properties are of interest in the study of the martensitic transformation, and the mutual relationship can be used to control SMA actuators. Moreover, this work could be very interesting from the point of view of applications because of the way of characterizing the SATWME activated by Joule effect (electrical heating), which could be a very normal situation of application in SMA actuators, like in an interrupter On/Off or a valve. In this work, experimental results recorded in electrical density cycles at several constant stresses are shown in figure 3 only for the most interesting states from the mechanical point of view, the M2 as-spun and $\mathrm{M} 2$ at $\mathrm{HT}-1$ at $50 \mathrm{~m} / \mathrm{s}$. The ribbons were loaded to a desired stress level in the austenitic state at $T>A f$, then they were cooled down below the $T<M f$ temperature under stress, and subsequently heated by Joule effect back to austenite phase above the $A f$ temperature. After one cycle, the stress was increased and a new cycle was carried out. In figure $3 \mathrm{a}$ the strain variation in function of the current density across the transformation range under different constant loads are showed for a ribbon as spun condition. In this same figure is indicated the way to measure the SATWME and the plastic strain $\left(\varepsilon_{\mathrm{p}}\right)$ which are plotted in the figure $3 \mathrm{~b}$. A small load (close to zero marked as P) was necessary in order to start the test with the ribbons completely straight. At around $0 \mathrm{MPa}$ (figure $3 \mathrm{~b}$ ) an important strain recovery of almost $2 \%$ can be observed, which can be related to a reorientation of martensite variants during the melt spinning process in the direction of the wheel rotation. This phenomenon has been previously observed during cold drawing ${ }^{30}$ and cold rolling ${ }^{31}$, the TiNi base alloy has shown a strong variant anisotropy in the direction of the fabrication process, this can be easily observed because these samples show a strain recovery without any applied stress after the elaboration process and a heat treatment, i.e. in curves of strain vs. temperature at $0 \mathrm{MPa}$, they present a strain or a displacement in the direction of the process, which is actually a Two Way Memory Effect (TWME). Then in the figure 3b, it can be observed that the SATWME increases with the stress, but very soon, at around $70 \mathrm{MPa}$, the SATWME reaches its stability, and after $240 \mathrm{MPa}$ an apparent loose of SATWME seems to take place. On the other hand, the plastic strain $\varepsilon_{\mathrm{p}}$ increases lineally with the stress and the R-phase is observed at the beginning of almost all the curves.

Now if the sample is heat treated at $350{ }^{\circ} \mathrm{C}$ during 1 hour (figure $3 \mathrm{c}$ and d), a small strain recovery of $0.4 \%$ at around $0 \mathrm{MPa}$, is observed. This means that the effect of the reorientation of martensite variants during the melt spinning process described above, is almost lost. Consequently the SATWME is also affected; there is also a diminution of the maximum SATWME with only $3 \%$, and the stability is reached until $180 \mathrm{MPa}$. The plastic strain $\varepsilon_{\mathrm{p}}$ also increases lineally with the stress but the R-phase is not clearly developed as for the as-spun condition. These results indicate that the 

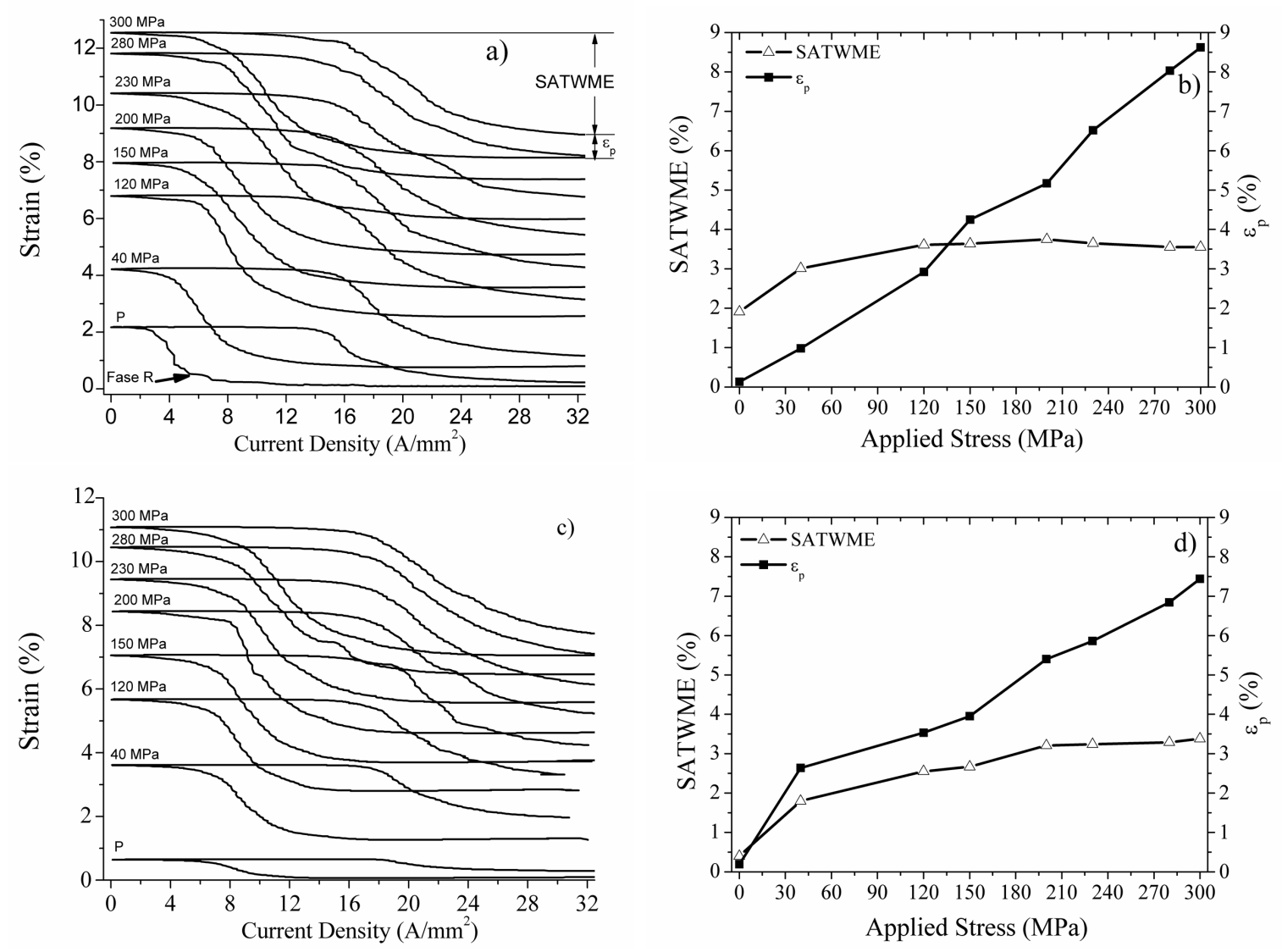

Figure 3. Strain-Current Density during thermal cycles under different constant stresses for M2 ribbons processed at $50 \mathrm{~m} / \mathrm{s}$, a) as-spun, c) annealed at HT-1, b) and d) show SATWME (open symbols) versus plastic deformation (filled symbols) for as-spun and annealed respectively

heat treatment process at $350^{\circ} \mathrm{C}-1 \mathrm{~h}(\mathrm{HT}-1)$, is not entirely beneficial, because annealed ribbons show lower values of SATWME, and the strain recovery close to $0 \mathrm{MPa}$ induced by the spun process and also the good stability were lost. Then, heat treatments of lower temperature or with less time of duration must be studied in future works. Moreover studies with $\mathrm{TiNiCu}$ ribbons are suggested to be explored with same conditions, in order to avoid the R-phase.

As it was mentioned by Wada and Liu ${ }^{32}$, there is a strong relation between the increase in SATWME and the increase in plastic strain $\left(\varepsilon_{\mathrm{p}}\right)$, and this can be explained from the viewpoint of a work-hardening effect attributed to the increase in dislocation density; thermomechanical cycling and stress at the initial stage causes a rapid increase in dislocation density, but then after cycling is more difficult to develop. Furthermore, during the thermomechanical cycles, a dislocation network has been developed that was most favorable to the internal stress field ${ }^{33}$, which in turn causes the martensite variants to be aligned in preferential orientation, making it possible to develop the SATWME. In this work, these results of accumulated cycles seem to indicate that the best compromise between aligned martensite variants (SATWME) or full utilization of the martensite reorientation capacity and dislocation density for M2 as spun, will take place between the 85 and $150 \mathrm{MPa}$ and for the M2 with HT1 between 180 and $240 \mathrm{MPa}$.

\section{Conclusions}

All states, including the as-spun ribbons obtained by melt spinning process, present the reversible austenite $\leftrightarrow$ martensite transformation, validating this process for elaborating equiatomic NiTi ribbons. Ribbons processed by this method did not exhibit the typical forward and reverse "S" shape of classical martensitic transformation of SMAs, opening the possibility to use these ribbons with small transformation hysteresis $(B 2 \rightarrow R)$, if a small recovery of strain is desirable. Chemical composition had an important role in the thermal and electrical behavior of quasi-equiatomic TiNi SAMs. It has been demonstrated in this work that variations on any of these elements, affect the transformation temperature, e.g. an increase in the NiTi content, tends to decrease the $\mathrm{M}_{\mathrm{s}}$ temperature and more $\mathrm{R}$-phase is detected. On the other hand, the increase in the spun velocity, promotes the presence of $\mathrm{R}$-phase. Then, the obtained results indicate that the combination of higher spun velocity with Ni-rich alloy should be desirable if R-phase is wanted. Results obtained from SATWME curves indicate that, orientation of martensite variants under load is a process that can be activated even at very low stress levels, reaching values of strain recovery close to $3.7 \%$, an important value for microactuators applications. Heat treatment after as spun condition is not entirely beneficial for spun ribbons, because 
annealed ribbons show lower values of SATWME. The ER apparatus used in this work, can be proposed for measuring electrical resistance variations in function of temperature, being good and effective alternative in the detection of phases present in alloys which show martensitic transformation. Finally, the developed Apparatus of Thermomechanical cycles to study SATWME, is a good alternative to characterize SMAs ribbons, and the results of Strain vs Current Density can be used directly to predict the expected mechanical behavior in a actuator activated by Joule Effect. Moreover, other geometries could be analyzed in this equipment, such as wires and small bars.

\section{References}

1. Nam TH, Kim JK, Choi MS, Kim YW, Im HJ, Jeung-Sun $\mathrm{A}$, et al. R phase transformation in equiatomic TiNi alloy ribbons fabricated by rapid solidification. Journal of Materials Science Letters. 2002;21(9):685-688. DOI:10.1023/A:1015720602368

2. Torres Castro A, López Cuéllar E, Ortiz Méndez U, Yacamán MJ. Crystal structure of TiNi nanoparticles obtained by $\mathrm{Ar}$ ion beam deposition. Materials Science and Engineerging $A$. 2008;481-482:476-478.DOI:10.1016/j.msea.2007.01.192

3. Nishida M, Hara T, Ohba T, Yamaguchi K, Tanaka K, Yamauchi $\mathrm{K}$. Experimental consideration of multistage martensitic transformation and precipitation behavior in aged Ni-rich Ti-Ni shape memory alloys. Materials Transactions. 2003;44(12):26312636.

4. Ma N, Song G, Lee HJ. Position control of shape memory alloy actuators with internal electrical resistance feedback using neural networks. Smart Materials and Structures. 2004; 13(4):777-783.

5. Uchil J, Mohanchandra KP, Mahesh KK, Ganesh Kumara K. Thermal and electrical characterization of R-phase dependence on heat-treat temperature in Nitinol. Physica B. 1998;253:83-89.

6. Resnina N, Belyaev S. Multi-stage martensitic transformations induced by repeated thermal cycling of equiatomic TiNi alloy. Journal of Alloys and Compounds. 2009;486(1-2):304-308. DOI:10.1016/j.jallcom.2009.06.132

7. Gonzalez CH, Oliveira CA, Cabral de Pina EA, Urtiga Filho SL, Araújo Filho OO, De Araújo CJ. Heat treatments and thermomechanical cycling influences on the R-Phase in Ti-Ni shape memory alloys. Materials Research .2010;13(3):325-331. DOI:10.1590/S1516-14392010000300008

8. Li YF, Mi XJ, Tan J, Gao BD. Thermo-mechanical cyclic transformation behavior of Ti-Ni shape memory alloy wire. Materials Science and Engineering A. 2009;509(1-2):8-13. doi:10.1016/j.msea.2009.02.041

9. Oliveira CA, Gonzalez CH, Urtiga Filho SL, da Silva N.J. Tratamentos térmicos e efeito do envelhecimento eletrotérmico na evolução da transformação de fase de ligas de Ti-Ni. Revista Eletrônica de Materiais e Processos. 2011;6(2):77-83. http:// www2.ufcg.edu.br/revista-remap/index.php/REMAP/article/ viewFile/172/197

10. Airoldi G, Lodi DA, Pozzi M. The electric resistance of shape memory alloys in the pseudoelastic regime. Journal of Physique IV Colloque. 1997;7:C507-C512. https://hal.inria.fr/file/index/ docid/255680/filename/ajp-jp4199707C580.pdf

11. Wu SK, Lin HC, Lin TY. Electrical resistivity of Ti-Ni binary and $\mathrm{Ti}-\mathrm{Ni}-\mathrm{X}(\mathrm{X}=\mathrm{Fe}, \mathrm{Cu})$ ternary shape memory alloys. Materials Science and Engineering A. 2006;438-440:536-539. doi:10.1016/j.msea.2005.12.059

\section{Acknowledgments}

Authors wish to thank to the CONACYT and CIAM for their financial support from the 82515 and 107462 projects. This work was technical supported by FIME-Universidad Autónoma de Nuevo León (UANL), Centro de Innovación, Investigación y Desarrollo en Ingeniería y Tecnología (CIIDIT), Multidisciplinary Laboratory on Active Materials and Structures, Department of Mechanical Engineering, Universidade Federal de Campina Grande, Brazil and Technological Institute of Aeronautics, São José dos Campos, SP, Brazil.

12. Novák V, Šittner P, Dayananda GN, Braz-Fernandes FM, Mahesh $\mathrm{KK}$. Electric resistance variation of NiTi shape memory alloy wires in thermomechanical tests: Experiments and simulation. Materials Science and Engineering A. 2008;481-482:127-133. doi:10.1016/j.msea.2007.02.162

13. López Cuéllar E, Guénin G, Morin M. Behaviour of strainresistivity coupled measurements of $\mathrm{Ti}-\mathrm{Ni}-\mathrm{Cu}$ wires during thermal cycling under constant stress. Materials Science and Engineering A. 2004;378(1):115-118. doi:10.1016/j. msea.2003.10.333

14. Nam TH, Noh JP, Jung DW, Kim YW, Im HJ, Ahn JS, et al. The R phase transformation in Ti-49 Ni (at.\%) shape memory alloy ribbons fabricated by melt spinning. Journal of Materials Science Letters. 2002;21, 11-13.

15. Chang SH, Chen TH, Wu SK, Lin KN. Damping characteristics of the Ti-rich TiNi melt-spun ribbon measured by using a dynamic mechanical analyzer. Physica Scripta. 2010;T139:1-5.

16. Šittner P, Landa M, Lukas P, Novák V. R-phase transformation phenomena in thermomechanically loaded NiTi polycrystals. Mechanics of Materials. 2006;38(5-6):475-492. DOI: 10.1016/j. mechmat.2005.05.025

17. Uchil J, Mahesh KK, Ganesh Kumara K. Electrical resistivity and strain recovery studies on the effect of thermal cycling under constant stress on R-phase in NiTi shape memory alloy. Physica B. 2002;324(1):419-428. DOI: 10.1016/S09214526(02)01462-X

18. De Araújo CJ, Morin M, Guénin G. Electro-thermomechanical behaviour of a Ti-45.0Ni-5.0 Cu (at.\%) alloy during shape memory cycling. Materials Science and Engineering A. 1999;273-275:305-309.

19. Song H, Kubica E, Gorbet R. Resistance modelling of SMA wire actuators. In: International Workshop Smart Materials Structures \& NDT in Aerospace. 2011 Nov 2-4. Montreal, Quebec. http:// www.ndt.net/article/ndtcanada2011/papers/66_Gorbet_Rev2. pdf

20. Potapov PL, Da Silva EP. Time response of shape memory alloy actuators. Journal of Intelligent Material System and Structures. 2000;11:125-134.

21. Otubo J, Rigo OD, Moura Neto C, Mei, PR. The effects of vacuum induction melting and electron beam melting techniques on the purity of NiTi shape memory alloys. Materials Science and Engineering A. 2006;438-440:679-682. doi:10.1016/j. msea.2006.02.171

22. Otubo J, Rigo OD, Coelho AA, Moura Neto C, Mei PR. The influence of carbon and oxygen content on the martensitic transformation temperatures and enthalpies of NiTi shape memory alloy. Materials Science and Engineering A. 2008;481482:639-642. doi:10.1016/j.msea.2007.02.137 
23. Mehrabi K, Bruncko M, McKay BJ, Kneissl AC. Influence of quenching rates on equiatomicNiTi ribbons fabricated by meltspinning. Journal of Materials Engineering and Performance. 2009;18(5-6): 475-478. DOI: 10.1007/s11665-009-9396-8

24. Lima WM, De Araújo CJ, Valenzuela WA, Rocha Neto JS. Electrical resistance measurements in shape memory alloy actuators for the position control of flexible systems - application to the case of an aluminum beam. In: International Workshop Smart Structures and Materials 2009 Jan 11-14. Porto, Lisboa.

25. Núñez Mendoza E. Elaboración y caracterización de cintas base Ni-Ti con memoria de forma producidas por solidificación rápida para su aplicación como actuadores.[Thesis]. Nuevo León, México: Universidad Autónoma de Nuevo León; 2013.

26. De Araújo CJ, Da Silva NJ, Da Silva MM, Gonzalez CH. A comparative study of $\mathrm{Ni}-\mathrm{Ti}$ and $\mathrm{Ni}-\mathrm{Ti}-\mathrm{Cu}$ shape memory alloy processed by plasma melting and injection molding. Materials \& Design. 2011;32:4925-4930.

27. Otsuka K, Wayman CM. Shape Memory Materials. Cambridge, UK: Cambridge University Press; 1998.

28. Nuñez Mendoza E, López Cuéllar E, De Castro WB, López Walle B. Effect of the linear velocity during the melt spinning process on shape memory transformation of $\mathrm{Ni}$-Ti ribbons.
Materials Research Society. 2012;1373:119-124. DOI: 10.1557 opl.2012.306

29. Liu Y, Humbeeck JV, Stalmans R, Delaey L. Some aspects of the properties of NiTi shape memory alloy. Journal of Alloys and Compounds. 1997;247:115-121.

30. Lopez Cuellar E, Guenin G, Morin M. Study of the stress-assisted two-way memory effect of a $\mathrm{Ti}-\mathrm{Ni}-\mathrm{Cu}$ alloy using resistivity and thermoelectric power techniques. Materials Science and Engineering A. 2003;358(1-2):350-355. DOI: 10.1016/S09215093(03)00328-9

31. Soto-Parra DE, Flores-Zuniga H, López-Cuellar E, Ochoa-Gamboa RA, Ríos-Jara D. Recrystallization of a Ti-45Ni-5Cu cold-worked shape memory alloy characterized by thermoelectric power and electrical properties. Materials Research. 2014;17(4):1023-1030. DOI:10.1590/1516-1439.265814

32. Wada K, Liu Y. Shape recovery of NiTi shape memory alloy under various pre-strain and constraint conditions. Smart Materials and Structures. 2005;14(5):S273-S286. DOI: 10.1088/09641726/14/5/016

33. Scherngell H, Kneissl AC. Training and stability of the intrinsic two-way shape memory effect in Ni-Ti alloys. Scripta Materialia. 1998;39(2):205-212. DOI: 10.1016/S1359-6462(98)00155-9 